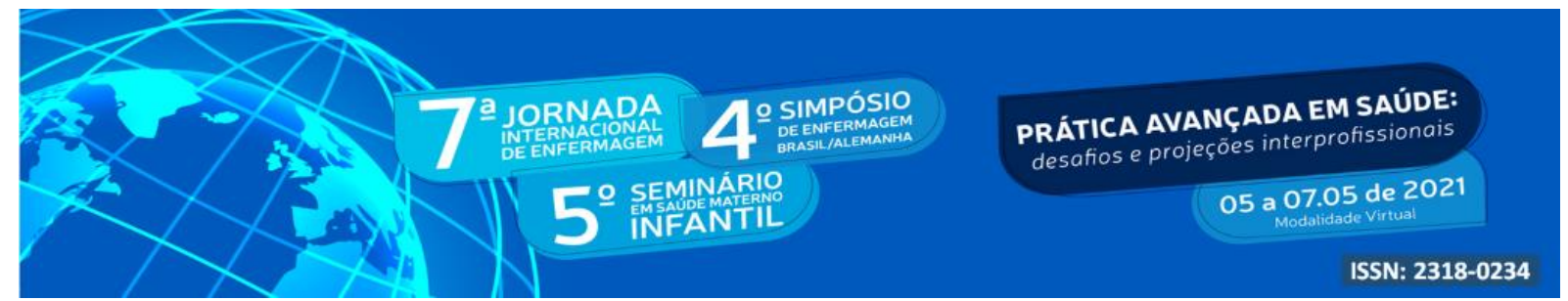

\title{
COMFORT FOOD EM TEMPOS DE PANDEMIA 1
}

DOI: http://doi.org/10.48195/jie2021-134

\author{
Marcelo de Carvalho Santos²; Melissa Coimbra Soares²; Morgana Silva da Fonseca²; \\ Ana Lúcia de Freitas $\mathrm{Saccol}^{3}$.
}

\begin{abstract}
RESUMO
O presente trabalho tem como objetivo relatar a experiência vivenciada na elaboração da atividade extensionista realizada na disciplina de educação em nutrição II, no período de isolamento social. A professora que ministra esta disciplina, trouxe uma proposta de atividade para os alunos, relacionada ao conceito de comfort food, onde seriam realizados um vídeo e um e-book com preparações elaboradas pelos acadêmicos relatando qual era o seu comfort food. Os acadêmicos tiveram uma experiência de ensino humanista sendo este valorizado pela instituição de ensino e realizado pelo curso. Possibilitou aos graduandos não apenas troca de conhecimentos, mas também a valorização de materiais feitos na disciplina e a publicação dos mesmos. Teve-se momentos de reflexão, discussão e sensibilidade emocional durante a apresentação. Conclui-se que foi possível desenvolver as atividades propostas de forma satisfatória, mesmo frente a todo o reajuste da disciplina em meio ao período de isolamento.
\end{abstract}

Palavras-chave: Afeto; Alimento; Isolamento social; Extensão.

\begin{abstract}
The present work aims to report the experience lived in the elaboration of the extension activity carried out in the discipline of education in nutrition II, during the period of social isolation. The teacher who teaches this discipline, brought an activity proposal for the students, related to the concept of comfort food, where a video and an e-book would be made with preparations prepared by the academics reporting what their comfort food was. The academics had a humanist teaching experience, which was valued by the educational institution and carried out by the course. It made it possible for undergraduates not only to exchange knowledge, but also to value materials made in the discipline and to publish them. There were moments of reflection, discussion and emotional sensitivity during the presentation. It was concluded that it was possible to develop the proposed activities in a satisfactory manner, even in the face of all the readjustment of the discipline in the middle of the isolation period.
\end{abstract}

Key words: Affection; Food; Social isolation; Extension

1. Trabalho extensionista, Disciplina Educação em Nutrição II, Curso de Nutrição. Universidade Franciscana (UFN)

2. Estudante do curso de Nutrição. UFN. E-mail: Marcelocarvalho@ufn.edu.br²; melissa.coimbra@ufn.edu.br ${ }^{3}$; m.silva@ufn.edu.br ${ }^{4}$.

3 Professora Orientadora. Doutora. Docente no curso de Nutrição e do Mestrado em Ciência da Saúde e da Vida. UFN. Coordenadora do Grupo de Pesquisa em Segurança Alimentar e Nutricional (GESAN/CNPq). E-mail: alsaccol@ufn.edu.br. 


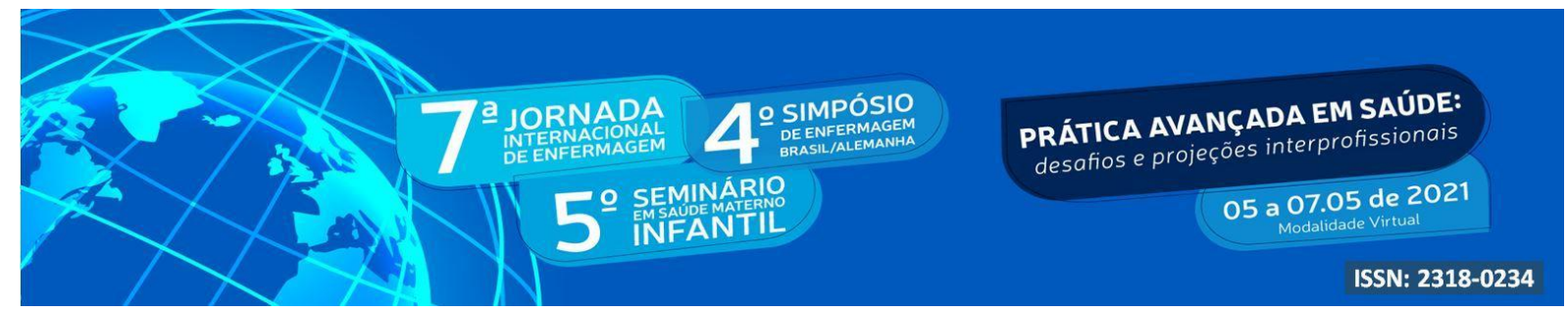

\section{INTRODUÇÃO}

O comer é uma ação concreta de incorporação tanto de alimentos como de seus significados, permeada por trocas simbólicas, envolvendo uma infinidade de elementos e de associações capazes de expressar e consolidar a posição de um agente social em suas relações cotidianas (CARVALHO; LUZ,2011). Ao comer tem-se muitas vezes a sensação de preenchimento de um vazio, algo que não se consegue explicar, mas que com determinados alimentos associados a lembranças boas gera um grande conforto. Muitas vezes durante um momento de tristeza e depressão ao comer um chocolate, ao beber um café quente, tem-se uma sensação de tranquilidade e até um tipo de saciedade daquele sentimento ruim. Mas ao comer também se sente prazer e satisfação, e isso pode se dar em momentos alegres, com amigos e familiares e ser muito reconfortante (OLIVEIRA; MAIRESSE, 2015).

O termo comfort food diz respeito a comidas e bebidas que possuem uma ligação com o passado percebido como mais feliz do que a realidade vivenciada naquele momento. Ao recorrer a determinada iguaria em momento de fragilidade, este consumo pode funcionar também como um mecanismo de reforço identitário, sendo acionado para fortalecer o vínculo a um determinado grupo. Isso se dá porque, embora exista uma tendência que aponte o consumo comfort foods como individual, o seu vínculo memorial com situações de comensalidade é evidente (GIMENES- MINASSE, 2016).

O conceito de comfort food, por exemplo, pode ser entendido como um dos esforços que buscam trabalhar a vertente das memórias gustativas ligadas em sua maioria ao contexto familiar e ao bem-estar, em outras palavras, destaca a importância das memórias gustativas na vida dos indivíduos e grupos. Este conceito, comfort food, pode ser considerado um tanto quanto novo no Brasil. Em uma tradução livre pode-se considerar aquele tipo de comida que desperta sensações agradáveis, prazer, bem-estar ligado à infância e história de vida (CALDEIRA, FAVA,2016).

O Brasil está passando por uma situação delicada, com uma crise econômica e na saúde com a disseminação da pandemia do COVID-19. A interseção dessas duas crises e a necessidade de isolamento social criam incertezas quanto à possibilidade de atender às necessidades humanas básicas devido à redução nos ganhos da população e à consequente queda no consumo e o potencial endividamento das famílias. A consequência mais imediata 


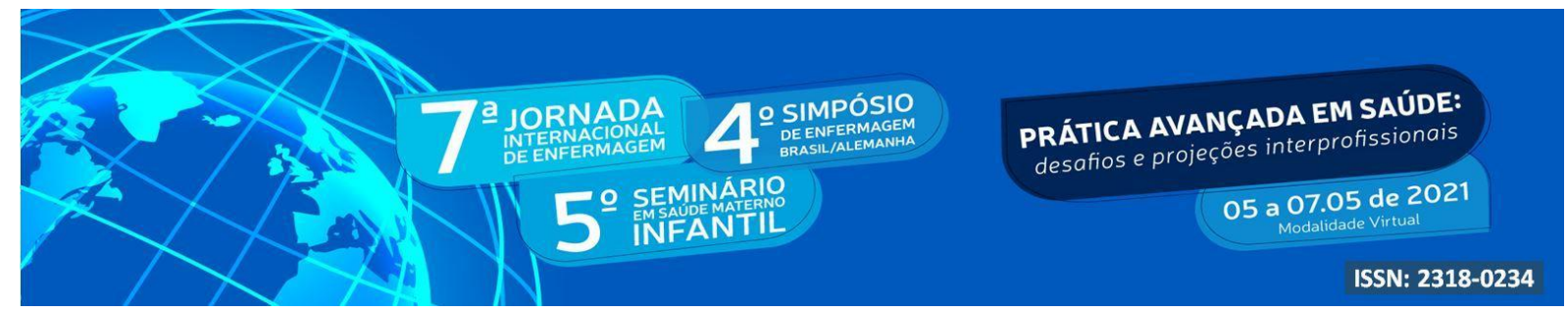

nesse cenário é a exacerbação da insegurança alimentar devido a restrições de renda que limitam o acesso aos alimentos (SILVA FILHO; GOMES JÚNIOR, 2020).

É consenso na literatura que diante de uma emergência de saúde pública a quarentena ou isolamento social podem desencadear diferentes sintomas psicológicos. Os sintomas mais comuns apontados pelos estudos foram, principalmente, ansiedade, medo, raiva e estresse, que trazem sofrimento para as pessoas que passam por esta situação, podendo ser agravadas ou instaladas mediante a vivência da quarentena ou isolamento social (VASCONCELOS, et $\mathrm{al}, 2020)$.

Neste contexto é importante relatar a experiência, vivência na elaboração da atividade extensionista realizada na disciplina de Educação em Nutrição II a fim de demonstrar como este conceito pode nos ajudar a enfrentar esse momento de tensão e incerteza através de atividades que trazem conforto e prazer.

\section{OBJETIVO}

O presente trabalho tem como objetivo relatar a experiência vivenciada na elaboração da atividade extensionista realizada na disciplina de educação em nutrição II, no período de isolamento social.

\section{METODOLOGIA}

$\mathrm{Na}$ atualidade vivencia-se um período de incertezas e medos como um todo, devido a pandemia de COVID-19, foram reformuladas todas as atividades educativas, sendo necessário reinventar-se. Devido a este contexto mundial, ocorreu a suspensão das atividades presenciais das universidades, fazendo com que os cursos dessa modalidade de ensino passassem a continuar suas atividades de forma remota. Com isso, a disciplina extensionista de Educação em Nutrição II do terceiro semestre do curso de Nutrição da Universidade Franciscana, que faria atividades nas escolas Estaduais do município de Santa Maria, RS, sofreu alterações no seu cronograma para que pudessem ser realizadas suas atividades de forma remota. No mês de maio de 2020, a professora que ministra esta disciplina, trouxe uma proposta de atividade para os alunos, relacionada ao conceito de comfort food, onde seriam realizados um vídeo e um e- 


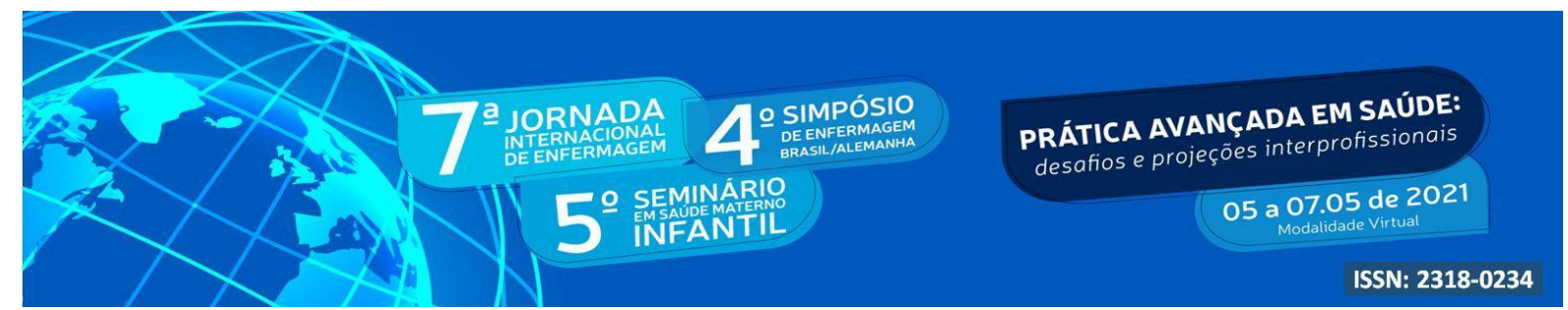

book com preparações elaboradas pelos acadêmicos da disciplina relatando qual era o seu comfort food.

A realização da atividade aconteceu em dois momentos, primeiramente, os acadêmicos deveriam ler artigos relacionados ao tema (GIMENES- MINASSE, 2016; SPENCE, 2017), pensar em qual preparação trazia este sentimento e elaborar a preparação e fazer os registros fotográficos, descrever o porquê da escolha do alimento e enviar para a elaboração do vídeo e do e-book. Em segundo lugar ocorreu a realização do vídeo e do e-book, realizados por alunos da própria disciplina.

O vídeo foi realizado no aplicativo InShOt ${ }^{\circledR}$, com duração de um minuto e quarenta e quatro segundo, começa com uma contextualização do termo comfort food e traz as fotos dos alunos com suas preparações e o relato do porquê se escolheu aquele alimento com o fundo do vídeo com alimentos remetendo ao tema e ao curso de Nutrição.

$\mathrm{O}$ e-book contém cinquenta e quatro páginas com a capa ilustrada com imagem de utensílios de cozinha com diferentes colheres de madeira de mexer preparações, logo em seguida vem uma introdução sobre comfort food com a citação de três artigos, apresenta um sumário com as preparações feitas, divididas em doce e salgadas, ao total foram realizadas 24 preparações. Primeiramente foram colocadas as preparações doces, a receita com modo de preparo e depois a foto de quem fez seguido da justificativa da escolha, em segundo plano, estava as preparações salgadas, seguindo a mesma lógica, receita e seu modo e a foto com a justificativa, todas as fotos contidas no e-book são as mesmas usadas para a elaboração do vídeo.

Depois de todas as preparações e as fotos, tem-se as referências e uma página final com pedindo que as pessoas ficassem em casa e com uma mensagem de esperança de que tudo ficará bem, há nesta página de identificação, a logomarca do curso de Nutrição e da Universidade Franciscana, além disso, traz o nome das colegas que foram responsáveis pela elaboração do ebook após toda preparação de ambos, os materiais foram registrados na biblioteca da Universidade Franciscana, ISBN: 978- 65- 991234-67 do vídeo e ISBN do e-book: 978-65991234-43 O período de duração da realização das atividades foi cerca de um mês.

\section{RESULTADOS E DISCUSSÃO}




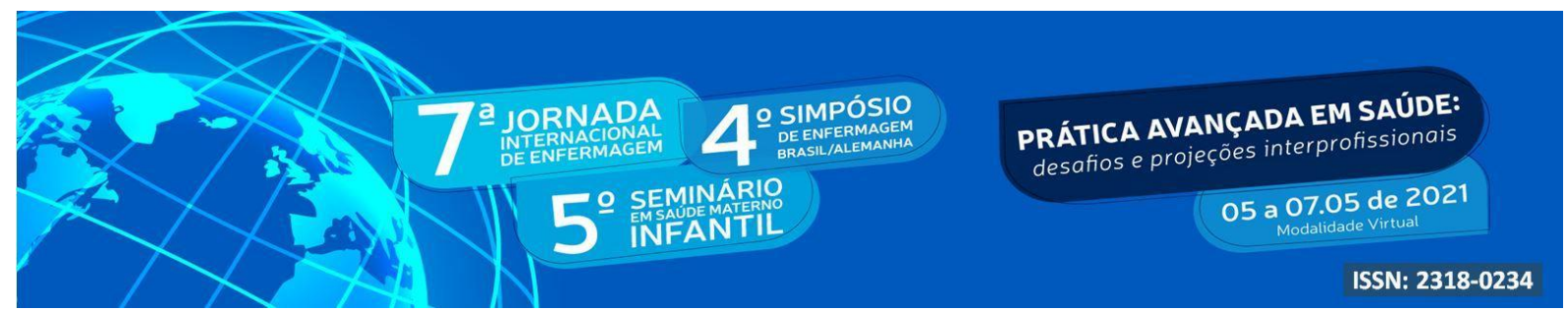

A partir da atividade extensionista realizada, os acadêmicos sentiram-se satisfeitos em poder colaborar com o projeto de extensão de forma remota e com a repercussão positiva da atividade. Outra potencialidade, foi a publicação do material e registro no Internationa Standard Book Number (ISBN), onde os alunos foram os autores principais. Com certeza essa atividade pode contribuir para elaboração de outros materiais educativos que possam ser úteis e servir de inspiração nas demais atividades extensionistas.

O processo de ensino por plataformas processa-se tanto por aulas em tempo real (síncronas), diretamente entre professor e aluno, quanto por aulas gravadas (assíncronas), com a exibição do material para a turma, disponibilizado por meio de plataformas tecnológicas. Ademais, deve-se mencionar a modalidade de atendimento personalizado à distância, com atenção individual aos alunos, uma espécie de trabalho tutorial. Os elementos e a experiência que compõem o processo de trabalho docente presencial precisaram ser readaptados a essa nova realidade, já que não se trata de uma mera transposição da atividade, antes modulada no ambiente de sala de aula em contato direto com os alunos(a)s, que passou a ser realizada integralmente em meio digital. Em termos concretos, a atividade de trabalho, o objeto e os seus meios precisaram ser redefinidos num curto espaço de tempo, sendo os próprios docentes responsáveis por esse processo (SOUZA, et al, 2020).

A situação pandêmica obrigou crianças, adolescentes e jovens a mudarem seus hábitos relacionais e de movimento, a estudarem de modo remoto, alguns com boas condições, com acesso à internet, com os suportes necessários (computador, tablet ou celulares), mas muitos não dispondo dessas facilidades, ou dispondo com restrições. Por exemplo, indisposição de rede de internet ou de computador ou outro suporte, posse de celulares pré-pagos com pouco acesso a redes; um só celular na família etc, contando ainda aqueles sem condição alguma para uso dos suportes tecnológicos escolhidos para suprir o modo presencial (GATTI,2020).

Com o isolamento social e a paralisação parcial das atividades nas instituições de ensino e a necessidade de modificar todo o planejamento da disciplina, a professora e os alunos da disciplina de Educação Nutricional II, trabalharam para oferecer sua contribuição às escolas que seriam trabalhadas as atividades práticas o mesmo conteúdo na forma remota, atendendo alunos, tanto com acesso à internet quando aqueles que não tinham acesso a tecnologias e internet, visando prestar apoio às escolas e contribuir para o processo de ensino. Portanto, todas as atividades eram encaminhadas virtualmente e caso necessário poderia ser feita a impressão 


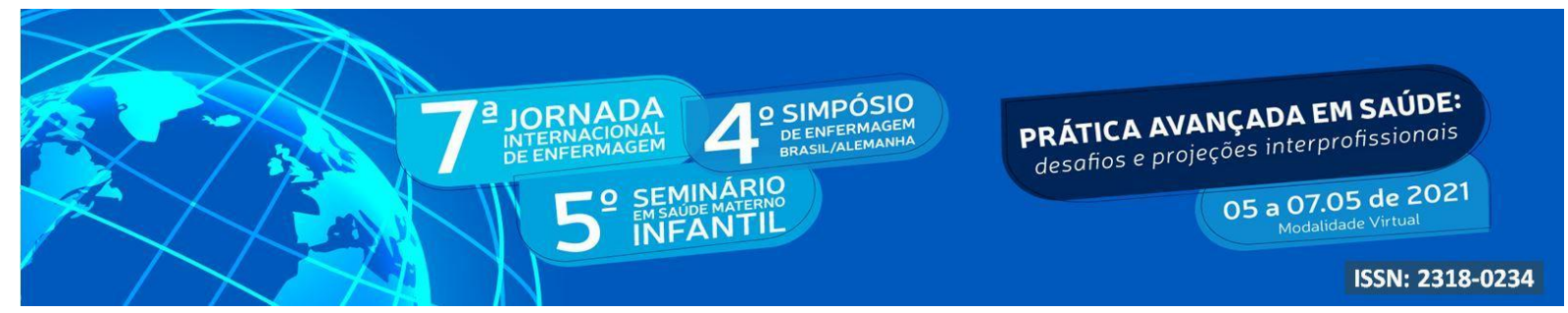

do material para ser entregue ao aluno. Com isso, mesmo frente às mudanças a disciplina obteve êxito no seu cronograma e planejamento sendo notado entre alunos e professora sentiram a necessidade de elaborar um material leve e instigante no final para encerrar essa experiência e assim teve-se a ideia de elaborar um vídeo e o e-book com a temática do comfort food. $\mathrm{Na}$ Figura 1 apresenta-se algumas imagens dos materiais produzidos.

Figura 1: Imagens E-Book Comfort Food, Disciplina de Educação em Nutrição II, Universidade Franciscana (UFN), Santa Maria, RS, Brasil, 2020.

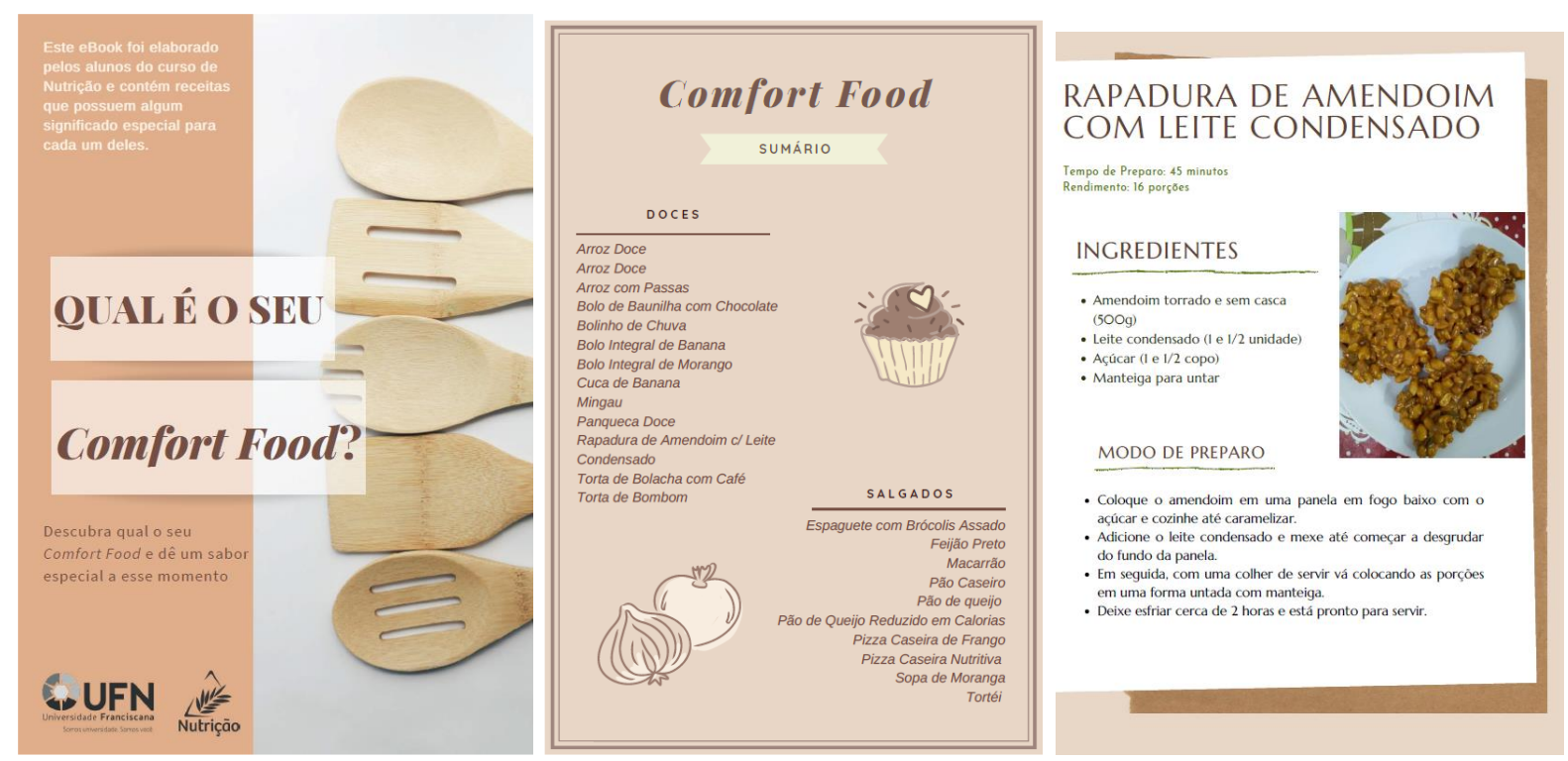

Fonte: SPAT, A.V; ARBOITH, G.S; BARROSO, I. R. Qual seu comfort food?. Universidade Franciscana. Santa Maria, 2020.

A partir da criação do e-book, observou-se que as receitas, as histórias e os sentimentos por trás de cada preparação feita, verificou-se que esta atividade estimulou a lembrança e os sentimentos por meio de alimentos feitos em casa e passados de geração em geração. No decorrer do desenvolvimento do e-book, notou-se a expectativa e apreensão para o resultado do trabalho e a sensação boa que esta atividade proporcionou no meio deste período de apreensão e isolamento em todos os acadêmicos da disciplina.

O vídeo elaborado a partir dos trabalhos de todos os estudantes abordou as receitas e os relatos de uma forma leve, tecnológica e com fluidez visual, resultando em uma abordagem parecida com o conceito que o comfort food traz a proposta da atividade (Figura 2). Tanto o ebook quanto 


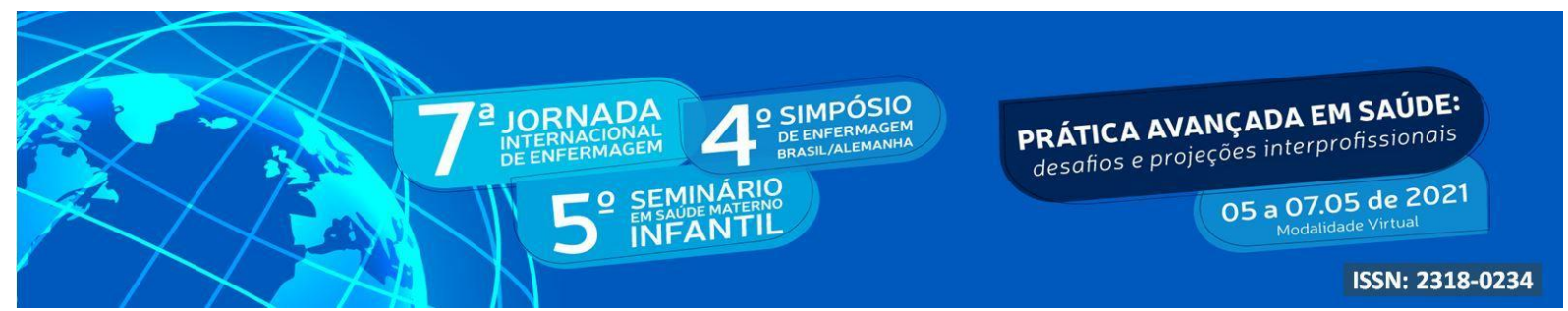

o vídeo, expressaram todo o eixo temático que a atividade propôs, combinando conhecimento de uma forma clara e de fácil compreensão, possibilitando, trocas de vivências e estreitamento de laços entre colegas e professora.

Figura 2: Imagens Vídeo Comfort Food, Disciplina de Educação em Nutrição II, Universidade Franciscana (UFN), Santa Maria, RS, Brasil, 2020.

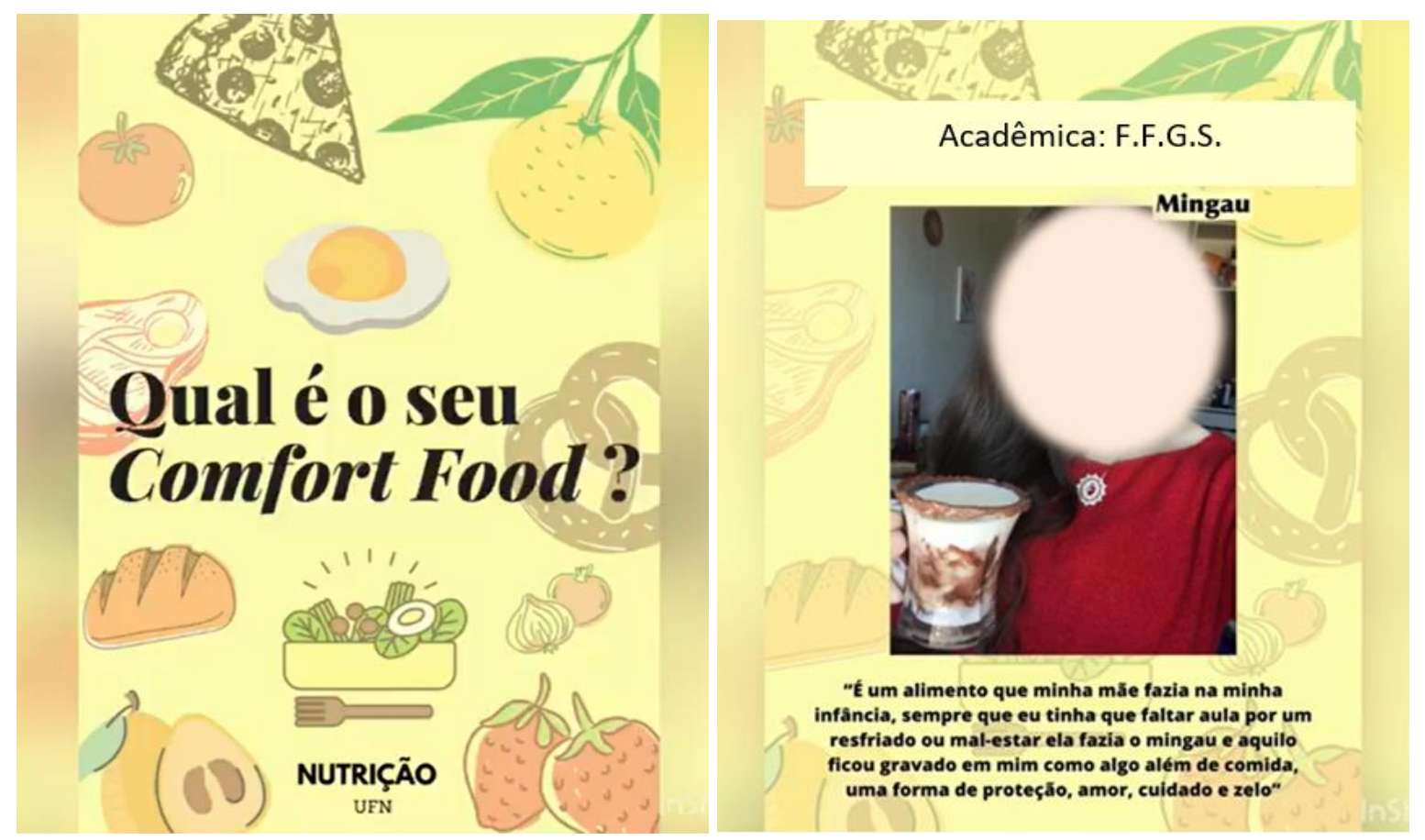

Fonte: SPAT, A.V; ARBOITH, G.S; BARROSO, I. R. Qual seu comfort food?. Universidade Franciscana. Santa Maria, 2020.

Ao final da discussão sobre o resultado final da atividade durante a aula foi possível sentir- se bem e entender o que este conceito vem trazer. Para fortalecer esta afirmação, logo a seguir serão expostos relatos de estudantes que fizeram parte desta atividade.

"Quando foi proposta a atividade, logo me lembrei do pão caseiro que minha avó fazia, o qual, toda minha família deliciava-se nos cafés de sábado à tarde. Como minha especialidade não é cozinhar, relatei o meu trabalho e pedi ajuda para minha mãe, a qual, tem a receita do pão da avó e realizamos juntas a preparação. Depois de tudo feito contei a minha avó a realização da atividade e expliquei para ela o termo comfort food e falei para ela que escolhi o pão dela porque ele me remete todo o amor, carinho, cuidado que temos uma pela outra." (Acadêmica 1).

Com estes breves relatos percebem-se o quanto foi gratificante, e reconfortante pensar em que alimento, em como fazer, qual seria o resultado final, e como os estudantes vibraram contando sua experiência. Isso foi reconfortante e trouxe um momento de tranquilidade para todos em meio a este momento de incertezas e medo da atualidade. 


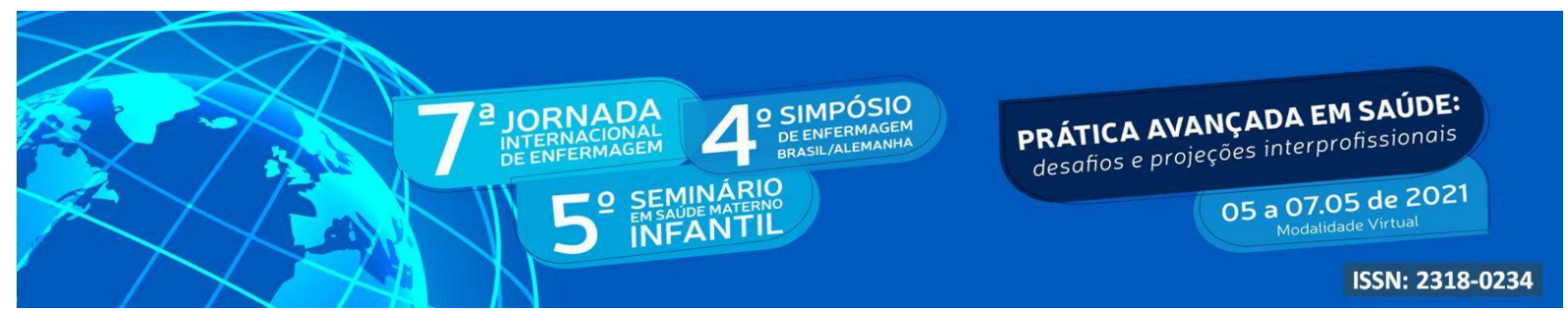

Com a crise financeira instalada no Brasil e junto a ela a Pandemia do Covid-19 muitas famílias não têm a possibilidade de escolhas por alimentos mais saudáveis o que poderá implicar no período pós pandêmico em doenças crônicas não transmissíveis (DCNT) como como a obesidade, hipertensão e diabetes. Com o avanço da pandemia da covid-19, notou-se conforme Bolsoni-Lopes et al (2021) que a obesidade é um dos fatores de risco para a infecção causada pelo coronavírus pois ela precede outras DCNT que são prejudiciais a melhora de condição de saúde de um paciente infectado pelo vírus. Mas a obesidade é considerada um fator de risco modificável, ou seja, com a melhora dos hábitos alimentares e do estilo de vida essa doença pode ser amenizada.

Segundo (MALTA, et al,2020) adultos com DCNT sofrerem maiores mudanças no seu estilo de vida, principalmente, na redução da prática de atividade física em meio a pandemia, com isso, ocorreu aumentando do sedentarismo e do consumo de alimentos ultraprocessados. Dessa forma a adoção de políticas públicas com o objetivo de promoção da saúde e prevenção de doenças, são importantes para evitar o crescimento da epidemia de DCNT nos pós pandemia e garantir uma boa adesão ao tratamento de pessoas que já apresentam alguma dessas comorbidades.

A elaboração do Vídeo e do e-book trouxe a oportunidade para que seja incentivado e valorizado o preparo de alimentos em casa e a escolha de receitas que trazem lembranças. Além de estar relacionada com o aspecto emocional, a história associada a alguns alimentos, lembranças que eles reproduzem para cada pessoa, fez com que fosse retomado de uma forma muito agradável para cada aluno a importância do vínculo do alimento com momentos, aromas, familiares e amigos. Através da escolha de uma preparação trouxe conforto de alguma forma. E o ato de poder compartilhar imagens dessas preparações com outras pessoas, num momento de fragilidade que a população está passando pode fortalecer o vínculo familiar através da escolha para a preparação de um alimento e a forma como será preparada faz toda diferença, a união de filhos e familiares e com a possibilidade de adaptação dessa receita sendo um momento que irá ficar guardado na memória.

A valorização da alimentação saudável e rica em nutrientes, em cores e sabores variados, traz grandes benefícios em todas as etapas da vida. Sendo necessário investir na educação alimentar e nutricional para a promoção dessa prática. Os melhores recursos pedagógicos para o ensino e aprendizagem alimentar e nutricional são aqueles que estimulam a participação e 


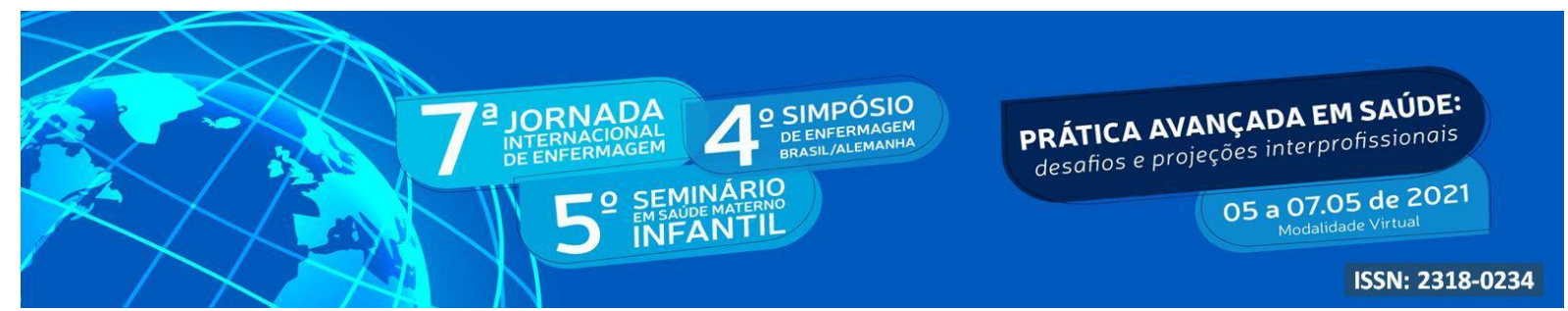

interação de todos os atores envolvidos, como encenações teatrais, debates, entrevistas, experiências práticas, entre outros. Nesses exemplos, há um maior contato entre os participantes, por meio do compartilhamento de informações, experiências vividas e diálogo que gera intimidade entre eles, sendo possível atingir os níveis emocionais e afetivos de cada indivíduo, promovendo um maior alcance e fixação das informações (PEREIRA; NUNES; MOREIRA,2020).

\section{CONCLUSÃO:}

O presente estudo mostra a realização de uma atividade extensionista educativa em período atípico, onde os acadêmicos do curso de nutrição tiveram uma experiência de ensino humanista sendo este valorizado pela instituição de ensino e realizado pelo curso. Possibilitou aos graduandos não apenas troca de conhecimentos, mas também a valorização de materiais feitos para a cadeira de Educação em Nutrição II. Ofertou um momento reflexão e sensibilidade durante a apresentação dos materiais. Conclui-se que foi possível desenvolver as atividades propostas de forma satisfatória, mesmo frente a todo o reajuste da disciplina em meio ao período de isolamento.

\section{REFERÊNCIAS}

BOLSONI-LOPES, A; FURIERI, L; AFONSO- VALE, M.I.C. Obesidade e a covid-19: uma reflexão sobre a relação entre as pandemias. Rev. Gaúcha de enfermagem, 2021. Disponível em: https://preprints.scielo.org/index.php/scielo/preprint/view/1512/2395.

CARVALHO, M.C.V.S; LUZ, M.T. Simbolismo sobre "natural" na alimentação. Ciência e saúde coletiva, Rio de Janeiro, 12 de julho de 2010. Disponível em:

https://www.scielo.br/pdf/csc/v16n1/v16n1a18.pdf.

CALDEIRA, R; FAVA, B.M. Comida: uma contadora de história. VIII Seminário Nacional do Centro de Memória- Unicamp. São Paulo, 26 de junho de 2016. Disponível em: https://www.cmu.unicamp.br/viiiseminario/wp-content/uploads/2017/05/Comida-umacontadora-de-historias-REGIANE-CALDEIRA-BRUNA-MENDES-FAVA.pdf.

FILHO, O.J.S; JÚNIOR, N.N.G. The future at the kitchen table: COVID-19 and the food supply. Caderno de saúde pública. Rio de Janeiro; 2020. Disponível em: https://www.scielosp.org/article/csp/2020.v36n5/e00095220/en/. 


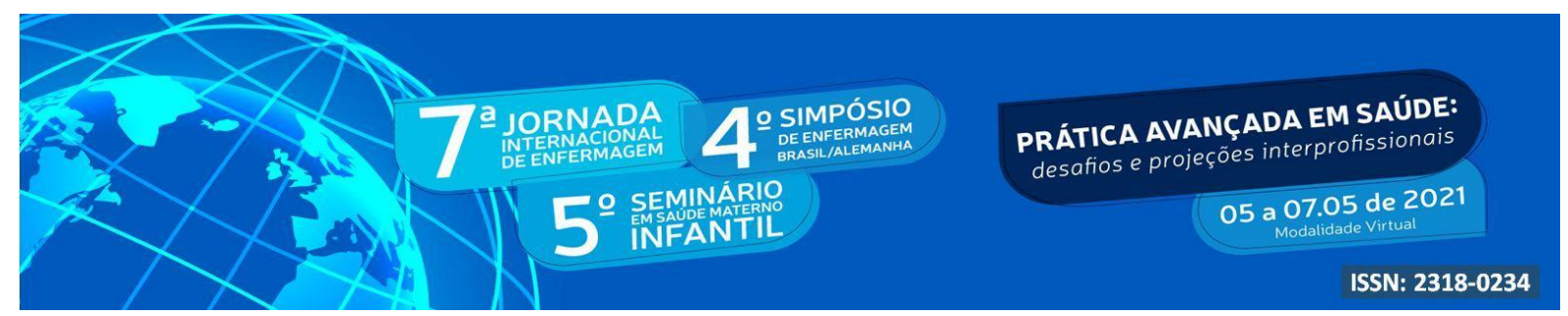

GATTI, A.B. Possível reconfiguração dos modelos educacionais pós-pandemia. Estudos avançados, v.19, n.100, 2020. Disponível em: https://www.scielo.br/pdf/ea/v34n100/18069592-ea-34-100-29.pdf.

GIMENES- MINASSE, M.H.S.G. Comfort food: sobre conceitos e principais características. Contextos da alimentação - Revista de Comportamento, Cultura e Sociedade, v. 2, 4 março, 2016; São Paulo. Disponível em: http://www3.sp.senac.br/hotsites/blogs/revistacontextos/wpcontent/uploads/2016/03/72_CA_artigo_revisado.pdf.

LIANG, L.Y. COVID-19 - A heavy burden on our minds, hearts and waistlines why obesity rates will rise and tips for prevention. The college of Family Physicians.

Disponível em: https://www.cfp.ca/news/2020/04/24/04-24-1.

MAIRESSE, L.D.K; OLIVEIRA, A.M.B. O conceito comfort food entre dois tipos de estabelecimentos de alimentação na cidade de Porto Alegre, 2015. Disponível em: http://www.repositorio.jesuita.org.br/handle/UNISINOS/5646?show=full.

MALTA, D.C et al. Doenças crônicas não transmissíveis e mudanças nos estilos de vida durante a pandemia de COVID-19 no Brasil. Minas Gerais, 2020. Disponível em: https://preprints.scielo.org/index.php/scielo/preprint/view/1621/2565.

PEREIRA, T.R; MOREIRA, B.; NUNES, R.M. A importância da educação alimentar e nutricional para alunos das séries iniciais. Educação em ciências - Relatos de experiência, Juiz de Fora, MG, v.1, n.1, 2020. Disponível em:

https://periodicos.ufjf.br/index.php/lynx/article/view/25591.

SOUZA, K.R; et al. Trabalho remoto, saúde docente e greve virtual em cenário de pandemia. Trabalho, educação, saúde, v.19, 2020. Disponível em: https://www.scielo.br/pdf/tes/v19/0102-6909-tes-19-e00309141.pdf.

SPAT, A.V; SACCOL. A. L. F; Qual o seu comfort food? Universidade franciscana - UFN, Santa Maria - RS, 2020.

SPENCE, C. Comfort food: A review. International Journal of Gastronomy and Food Science, Oxford, 2017. Disponível em: https://www.elsevier.com/locate/ijgfs.

VASCONCELOS,C.S; et al. O novo coronavírus e os impactos psicológicos da quarentena. Rev. Desafios, 22 de abril de 2020. Disponível em: https://sistemas.uft.edu.br/periodicos/index.php/desafios/article/view/8816/16731. 